University of Nebraska - Lincoln

DigitalCommons@University of Nebraska - Lincoln

Faculty Publications from the Harold W. Manter Laboratory of Parasitology

$12-1996$

\title{
Phylogenetic Analysis of Opisthadena (Digenea: Hemiuridae)
}

Virginia León-Règagnon

Universidad Nacional Autónoma de México

Gerardo Pérez-Ponce de León

Universidad Nacional Autónoma de México, ppdleon@servidor.unam.mx

Daniel R. Brooks

University of Toronto,dnlbrooks@gmail.com

Follow this and additional works at: https://digitalcommons.unl.edu/parasitologyfacpubs

Part of the Parasitology Commons

León-Règagnon, Virginia; Pérez-Ponce de León, Gerardo; and Brooks, Daniel R., "Phylogenetic Analysis of Opisthadena (Digenea: Hemiuridae)" (1996). Faculty Publications from the Harold W. Manter Laboratory of Parasitology. 285.

https://digitalcommons.unl.edu/parasitologyfacpubs/285

This Article is brought to you for free and open access by the Parasitology, Harold W. Manter Laboratory of at DigitalCommons@University of Nebraska - Lincoln. It has been accepted for inclusion in Faculty Publications from the Harold W. Manter Laboratory of Parasitology by an authorized administrator of DigitalCommons@University of Nebraska - Lincoln. 


\title{
PHYLOGENETIC ANALYSIS OF OPISTHADENA (DIGENEA: HEMIURIDAE)
}

\author{
Virginia León-Règagnon, Gerardo Pérez-Ponce de León, and Daniel R. Brooks \\ Laboratorio de Helmintología, Instituto de Biología, U.N.A.M., \\ Apdo. Postal 70-153 C.P. 04510, Del. Coyoacán, México, D.F., México
}

\begin{abstract}
Systematic study of the closely related hemiurid genera Mitrostoma, Neopisthadena and Opisthadena revealed that Opisthadena cortesi is a junior synonym of Opisthadena dimidia and Opisthadena fujianensis and Opisthadena marina are species inquirendae. Phylogenetic analysis of the 7 recognized species, based on 21 transformation series derived from comparative morphologic characters, produced a single tree with a consistency index of 0.735 . The five species of the genus Opisthadena constitute a monophyletic clade and Neopisthadena habei is their sister group. Mitrostoma nototheniae is the sister group of the other 6 members of the clade. Geographic distribution suggests an ancient circum-Pacific distribution of the group. The association between kyphosids and this group of hemiurids appeared with the ancestor of Neopisthadena and Opisthadena.
\end{abstract}

The Hemiuridae (sensu Brooks et al., 1985) is 1 of the most diverse, and characteristic, groups of digeneans inhabiting marine fishes. Gibson and Bray (1979) grouped together the genera Opisthadena Linton, 1910, Genolinea Manter, 1925, Neotheletrum Gibson and Bray, 1979, and Mitrostoma Manter, 1954 in the subfamily Opisthadeninae. Neopisthadena Machida, 1980 was described as a group closely related to Opisthadena. $\mathrm{Mi}$ trostoma and Neopisthadena are both monotypic; Mitrostoma nototheniae Manter, 1925 was described by Manter (1954) from Notothenia macrocephala (Günther) off New Zealand and Neopisthadena habei Machida, 1980 was described from Kyphosus cinerascens (Forskal) off Japan (Machida, 1980). Opisthadena comprises 8 nominal species. The type species, Opisthadena dimidia Linton, 1910, was first described from Kyphosus sectatrix (Linn.) and Kyphosus incisor (Cuvier and Valenciennes) off Florida (Linton, 1910). Opisthadena dimidia was subsequently recorded in Kyphosus spp. off Florida (Manter, 1947; Overstreet, 1969), the Pacific coast of Panama and the Caribbean Sea (Sogandares-Bernal, 1959), South Australia (Manter, 1966), Japan (Machida, 1980), the Caribbean Sea (Sierra, 1984), and the Pacific coast of México (León-Règagnon et al., 1997). The other species of Opisthadena have restricted geographic distributions. Opisthadena kuwaiti Al-Yamani and Nahhas, 1981 was described from the Arabian Gulf in Valamugil seheli (Forskal) (Al-Yamani and Nahhas, 1981). Opisthadena cortesi Bravo-Hollis, 1965 was described from Kyphosus elegans (Peters) off the Gulf of California (Bravo-Hollis, 1965). Yamaguti (1970) described Opisthadena kyphosi Yamaguti, 1970 from Kyphosus cinerascens off Hawaii. Opisthadena bodegensis Johnson and Copsey, 1953 and Opisthadena cheni Martin, 1978 were described off the coast of California from $\mathrm{Ce}$ bidichthys violaceus (Girard) (Johnson and Copsey, 1953) and Girella nigricans (Ayers) (Martin, 1978), respectively. Finally, Tang et al. (1983) described Opisthadena fujianensis Tang, Shi, Cao, Guan and Pan, 1983 and Opisthadena marina Tang, Shi, Cao, Guan and Pan, 1983 from Fujian, China, in Mugil engeli (Bleeker) and Ambassis gymnocephalus (Lacépède), respectively.

This study was undertaken to propose a hypothesis of the phylogenetic relationships of the species of Opisthadena, Neo-

Received 20 March 1996; revised 28 June 1996; accepted 28 June 1996.

* Department of Zoology, University of Toronto, Toronto, Ontario, Canada M5S 1A1. pisthadena, and Mitrostoma, and to examine the biogeographic and coevolutionary history of the group.

\section{MATERIALS AND METHODS \\ Specimens examined}

We examined all available published sources and the following specimens (species name followed by accession number ( ), number of examined specimens [ ], host, and locality): Colección Nacional de Helmintos, México City, México (CNHE): O. cortesi (898 P, 1379 P, 1483 P) [24] K. elegans, Baja California, México; O. dimidia (899 P, 2631 P, 2632 P) [9] K. incisor, Quintana Roo and $K$. elegans, Jalisco, México; Genolinea dactylopagri Manter, 1954 (2485 P) [1] Dactylopagrus macropterus (Forster), New Zealand; Genolinea laticauda Manter, 1925 (807 P) [9] K. elegans, Sonora, México; Neotheletrum lissosomum Manter, 1940 (1517 P) [1] "Angel fish," Socorro Island, México; Neotheletrum gravidum Manter, 1940 (999 P) [1] Abudefduf saxatilis (Linn.), Socorro and Clarión Islands, México; Parahemiurus merus (2633-2641 P) [53] Harengula thrissina (Jordan and Gilber) and Opisthonema libertate (Günther), Jalisco, México. United States National Parasite Collection, Beltsville, Maryland, U.S.A. (USNPC): O. dimidia (8489, 77751) [3] K. sectatrix, Florida and Puerto Rico; O. bodegensis (37338) [1] C. violaceus, California; O. kyphosi (63790) [5] K. cinerascens, Hawaii; M. nototheniae (49150) [1] Notothenia macrocephala, New Zealand; Genolinea dactylopagri (49151) [1] D. macropterus, New Zealand; Genolinea anura Layman, 1930 (49177) [1] Chironemus spectabilis (Hutton), Australia; Genolinea montereyensis Annereaux, 1947 (36952) [1] Clinocottus analis (Girard), California; Genolinea noblei Nahhas and Cable, 1964 (60290) [1] A. saxatilis, Jamaica. Meguro Parasitological Museum, Tokyo, Japan (MPM): O. kyphosi (15245) [4] $K$. cinerascens, Japan. National Science Museum Tokyo, Japan (NSMT): $N$. habei (Pl 2293) [5] K. cinerascens, Japan; O. dimidia (Pl 2234) [3] $K$. cinerascens, Japan. We were unable to establish contact with the Hancock Parasite Collection (University of Southern California), where Opisthadena cheni is reportedly deposited. Moreover, the location of type specimens was not indicated in the original descriptions of Opisthadena kuwuaiti. Therefore, we based our character analysis for these 2 species on the original descriptions.

\section{Analyses performed}

Phylogentic analyses were performed using the methods of phylogenetic systematics (Hennig, 1966; Wiley, 1981; Wiley et al., 1991). Results were confirmed quantitatively using the PAUP (Phylogenetic Analysis Using Parsimony) computer program version 3.1.1. (Swofford, 1993), run on a Macintosh LCIII computer. The following options were examined: (1) characters: all unordered, or only character 18 unordered. (2) Outgroups: plesiomorphic conditions determined by the state observed in the genera Genolinea and Neotheletrum, which are recognized to be the most related genera of bunocotylids (Gibson and Bray, 1979) as a primary outgroup and the Hemiurini (Hemiurus, Parahemiurus, and Anahemiurus). The hemiurids were recognized to be the sister group of bunocotilids by Brooks et al. (1985) and within them, the hemiurini were considered to be the most related group of the bunocotilids (Gibson and Bray, 1979). (3) optimization: Acctran, Deltran. (4) Tree-building algorithms: exhaustive search. 
TABLE I. Data matrix for Opisthadena, Neopisthadena, and Mitrostoma. Characters are numbered as in the text; for descriptions of characters and polarity arguments, see text. $0=$ plesiomorhpic condition; $1,2=$ apomorphic conditions; ? = condition unknown.

\begin{tabular}{llllllllllllllllllllll}
\hline & \multicolumn{110}{c}{ Character } \\
\cline { 2 - 5 } & 1 & 2 & 3 & 4 & 5 & 6 & 7 & 8 & 9 & 10 & 11 & 12 & 13 & 14 & 15 & 16 & 17 & 18 & 19 & 20 & 21 \\
\hline HE & 0 & 0 & 0 & 0 & 0 & 0 & 0 & 0 & 0 & 0 & 0 & 0 & 0 & 0 & 0 & 0 & 0 & 0 & 0 & 0 & 0 \\
GE & 1 & 0 & 0 & 0 & 0 & 1 & 1 & 1 & 1 & 0 & 0 & 2 & 0 & 0 & 0 & 0 & 1 & 0 & 0 & 1 & 2 \\
NE & 1 & 0 & 0 & 0 & 0 & 0 & 2 & 1 & 0 & 0 & 0 & 2 & 0 & 0 & 0 & 0 & 1 & 0 & 1 & 1 & 2 \\
MN & 1 & 0 & 0 & 0 & 0 & 0 & 0 & 0 & 0 & 1 & 0 & 0 & 0 & 0 & 1 & 0 & 1 & 1 & 0 & 1 & 1 \\
NH & 1 & 0 & 0 & 0 & 0 & 1 & 0 & 0 & 0 & 0 & 0 & 0 & 0 & 0 & 1 & 1 & 1 & 0 & 1 & 1 & 1 \\
DI & 2 & 0 & 0 & 1 & 1 & 1 & 0 & 1 & 1 & 0 & 0 & 1 & 0 & 1 & 1 & 1 & 1 & 0 & 1 & 1 & 1 \\
CH & 2 & 1 & 1 & 0 & 0 & 1 & 0 & 0 & 1 & 1 & 0 & 1 & 1 & 0 & 1 & 1 & 1 & 0 & $?$ & 1 & 1 \\
KU & 2 & 1 & 0 & 0 & 0 & 0 & 0 & 0 & 0 & 0 & 1 & 1 & 0 & 0 & $?$ & 1 & 1 & 0 & $?$ & 1 & 1 \\
KY & 2 & 0 & 0 & 1 & 1 & 0 & 0 & 0 & 1 & 0 & 0 & 1 & 0 & 1 & 1 & 1 & 1 & 0 & 1 & 1 & 1 \\
BO & 2 & 0 & 1 & 0 & 1 & 1 & 0 & 0 & 1 & 0 & 0 & 1 & 0 & 1 & 1 & 1 & 1 & 0 & 0 & 1 & 1 \\
\hline
\end{tabular}

$* \mathrm{HE}=$ Hemiurini (outgroup); GE = Genolinea $($ outgroup) $; \mathrm{NE}=$ Neotheletrum $($ outgroup) MN = Mitrostoma nototheniae $;$ NH = Neopisthadena habei DI = Opisthadena dimidia $; \mathrm{CH}=O$. chen $; \mathrm{KU}=O$. kuwait $; \mathrm{KY}=O$. kyphosi $; \mathrm{BO}=O$. bodegensis.

\section{RESULTS}

\section{Taxa recognized}

Of the 10 nominal species in this group, we recognize 7 as valid in this study; 5 species of Opisthadena and the monotypic Neopisthadena habei, and Mitrostoma nototheniae. Overstreet (1969) synonymized $O$. cortes $i$ with $O$. dimidia. We examined the type specimens of $O$. cortesi and agree with Overstreet's evaluation. Machida (1980) proposed that $O$. kyphosi was synonymous with $O$. dimidia. He argued that the number of oral papillae was not a useful character for distinguishing species because in Japanese specimens of $O$. dimidia the number of oral papillae varied from 5 pairs, as originally described by Manter (1947), to 3 pairs. We have noticed the same variation in number of papillae in the specimens of $O$. dimidia that we examined, but we also found that at least 3 pairs of oral papillae are always present. Opisthadena kyphosi, by contrast, bears no oral papillae, and for that reason we consider it a valid species. Finally, $O$. fujianensis and $O$. marina were described based on a single specimen each, and the characters used to separate them from other species, such as body length, the presence of annulations in the tegument, and the shape of the genital cone, vary greatly with fixation techniques. The shape of vitelline masses in $O$. fujianensis indicates that this specimen might belong in the Lecithasterinae (sensu Brooks et al., 1985), and the male genital ducts of $O$. marina differ greatly from those of other members of Opisthadena. We therefore consider those taxa species inquirendae in this analysis.

\section{Character argumentation}

We used the following characters and their states in the phylogenetic analysis (characters are listed in order of their appearance in Table I; $0=$ plesiomorphic; $1,2=$ apomorphic; ? = unknown). The polarity argumentation for each character is:

1. Seminal vesicle. Three states: $0=$ saccate; $1=$ tubular; 2 $=$ seminal sac. In the species of the genus Opisthadena there is a sac containing a very coiled tubular seminal vesicle.

2. Egg size. Two states: $0=$ larger than $25 \mu \mathrm{m} ; 1=13-18$ $\mu \mathrm{m}$.
3. Pharynx size. Two states: $0=$ pharynx smaller than the oral sucker; $1=$ pharynx and oral sucker the same size.

4. Testes location. Two states: $0=$ in the second third of the body; $1=$ in the posterior third of the body.

5. Excretory ducts. Two states: $0=$ nonbranched anteriorly to the acetabulum; 1 = branched anteriorly.

6. Oral papillae. Two states: $0=$ absent; $1=$ present. As noted above, the number of oral papillae is variable within a species.

7. Testes position. Three states: $0=$ symmetrical; $1=$ oblique; 2 = tandem. In most of the genera of the Hemiurini (outgroup) testes are symmetrical, so we considered this state as plesiomorphic.

8. Distance between posterior testis and ovary. Two states: 0 $=$ posterior testis lies more than its own length from the ovary; 1 = posterior testis lies less than its own length from the ovary.

9. Location of the vitellaria and ovary. Two states: $0=$ in the third quarter of the body; $1=$ in the fourth quarter of the body.

10. Muscular sphincter around acetabulum. Two states: $0=$ absent; 1 = present.

11. Seminal vesicle wall. Two states: $0=$ thin; $1=$ thick.

12. End of pars prostatica. Three states: $0=$ at the level of acetabulum; $1=$ posterior to the acetabulum; $2=$ anterior to the acetabulum.

13. Acetabular papillae. Two states: $0=$ absent; $1=$ present. This is a unique state for $O$. cheni.

14. Extension of excretory ducts. Two states: $0=$ running forward of the acetabulum; 1 = forward of the acetabulum and back posteriorly to testes level.

15. Postacetabular transverse fold. Two states: $0=$ absent; $1=$ present. In the description of the Arabian species, there is no mention made of the presence or absence of the fold. Because we could not examine type specimens, we coded this character as "unknown" (?).

16. Ejaculatory duct. Two states: $0=$ absent; $1=$ present.

17. Seminal receptacle. Two states: $0=$ absent; $1=$ present.

18. Preacetabular pit. Two states: $0=$ absent; $1=$ present.

19. Excretory vesicle bifurcation. Two states: $0=$ near the posterior margin of the acetabulum; $1=$ at the level of testes. 


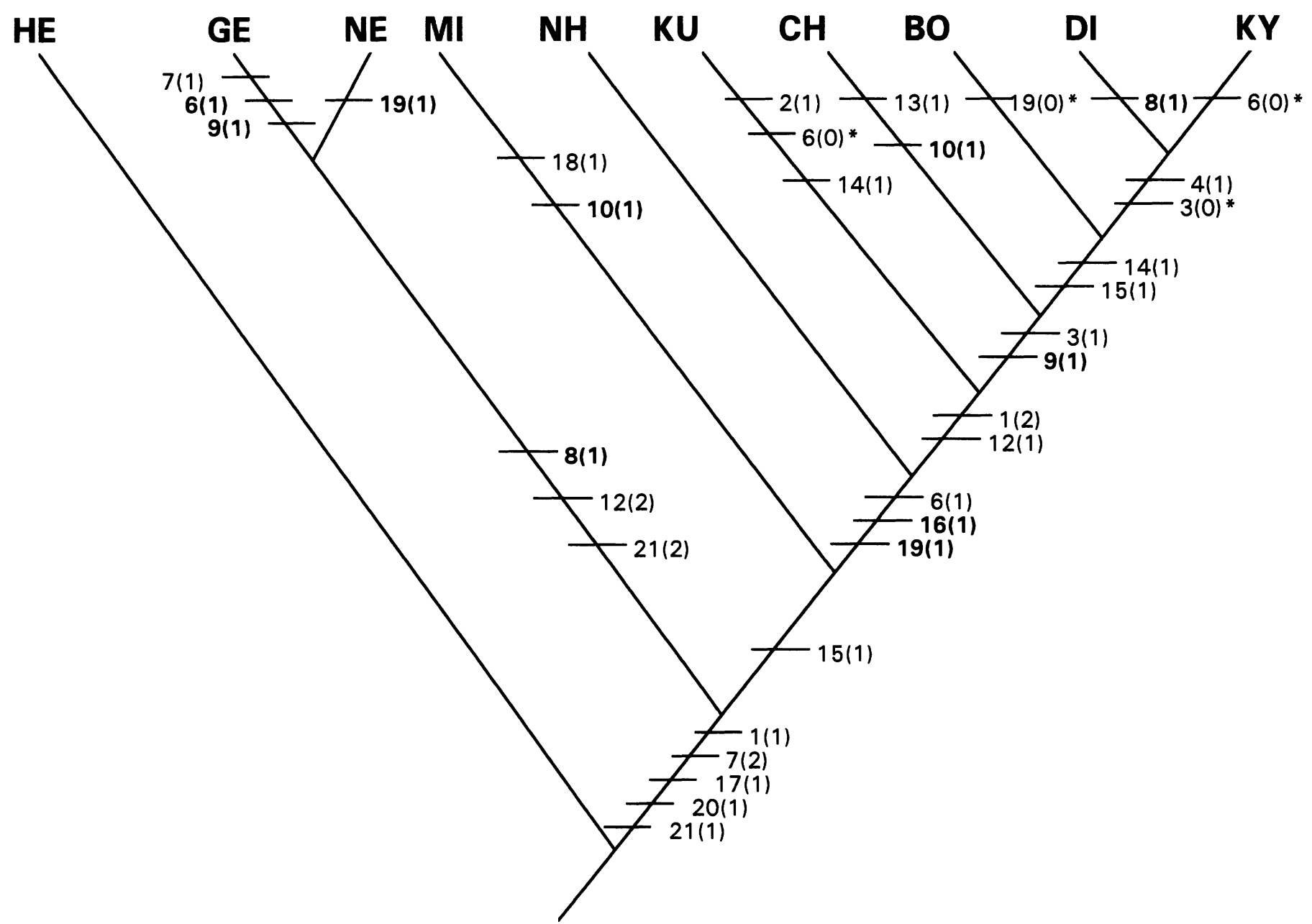

FIGURE 1. Phylogenetic tree for Mitrostoma nototheniae, Neopisthadena habei, and 5 species of Opisthadena. Numbers accompanying slash marks on the tree indicate putative synapomorphies (character number followed by character state in parentheses) supporting the phylogenetic relationships. For identities of characters, refer to text. Bold numbers, convergent or parallel character state; *, reversal. For character 3 , it is equally parsimonious to postulate that state " 1 " is a synapomorphy of $O$. cheni, $O$. bodegensis, $O$. kyphosi, and $O$. dimidia, with a reversal to state " 0 " in $O$. kyphosi plus $O$. dimidia, with no change in postulated relationships.

The condition of this character is not described in detail for $O$. kuwaiti and $O$. cheni, we coded this character as "unknown" (?) for those two species.

20. Uterine seminal receptacle. Two states: $0=$ present; $1=$ absent.

21. Vitelline masses position. Three states: $0=$ symmetrical; 1 = oblique; 2 = tandem.

\section{Phylogenetic analysis of Bunocotylinae}

Phylogenetic analyses of the 7 taxa we consider valid, using all combinations of above options, produced a single most parsimonious phylogenetic tree (Fig. 1), with a consistency index of 0.735 (34 transformations to account for 25 apomorphic states). This result predicts that $O$. kuwaiti possesses a postacetabular fold and that $O$. kuwaiti and $O$. cheni possess excretory vesicles that bifurcate at the level of the testes; verification of these predictions requires examination of specimens. Only 2 of the 34 evolutionary changes postulated by this tree represent an evolutionary loss (the loss of oral papillae in $O$. kyphosi and o. kuwaiti), indicating a minimal amount of secondary simpli- fication in the evolution of these parasites. The loss of the ecsoma and cuticular plications present in the Hemiurini are not considered herein because those are the result of a previous simplification event in some basal point of the ancestral states of bunocotilids. The tree supports the monophyly of Mitrostoma + Neopisthadena + Opisthadena; the presence of a postacetabular transverse fold is the synapomorphy diagnosing the clade. The tree further suggests that the monotypic Mitrostoma is the sister group of the remaining species and Neopisthadena habei is the sister species of the genus Opisthadena, which is monophyletic.

\section{DISCUSSION}

The level of homoplasy encountered in this study is comparable to those found in other phylogenetic systematic studies of digeneans (Brooks and McLennan, 1993a, 1993b; PérezPonce de León and Brooks, 1995a, 1995b), although substantially less than postulated by intuitive or evolutionary taxonomic studies (e.g., Pearson, 1992). The low amount of simplification in this genera of bunocotilids provides additional support 


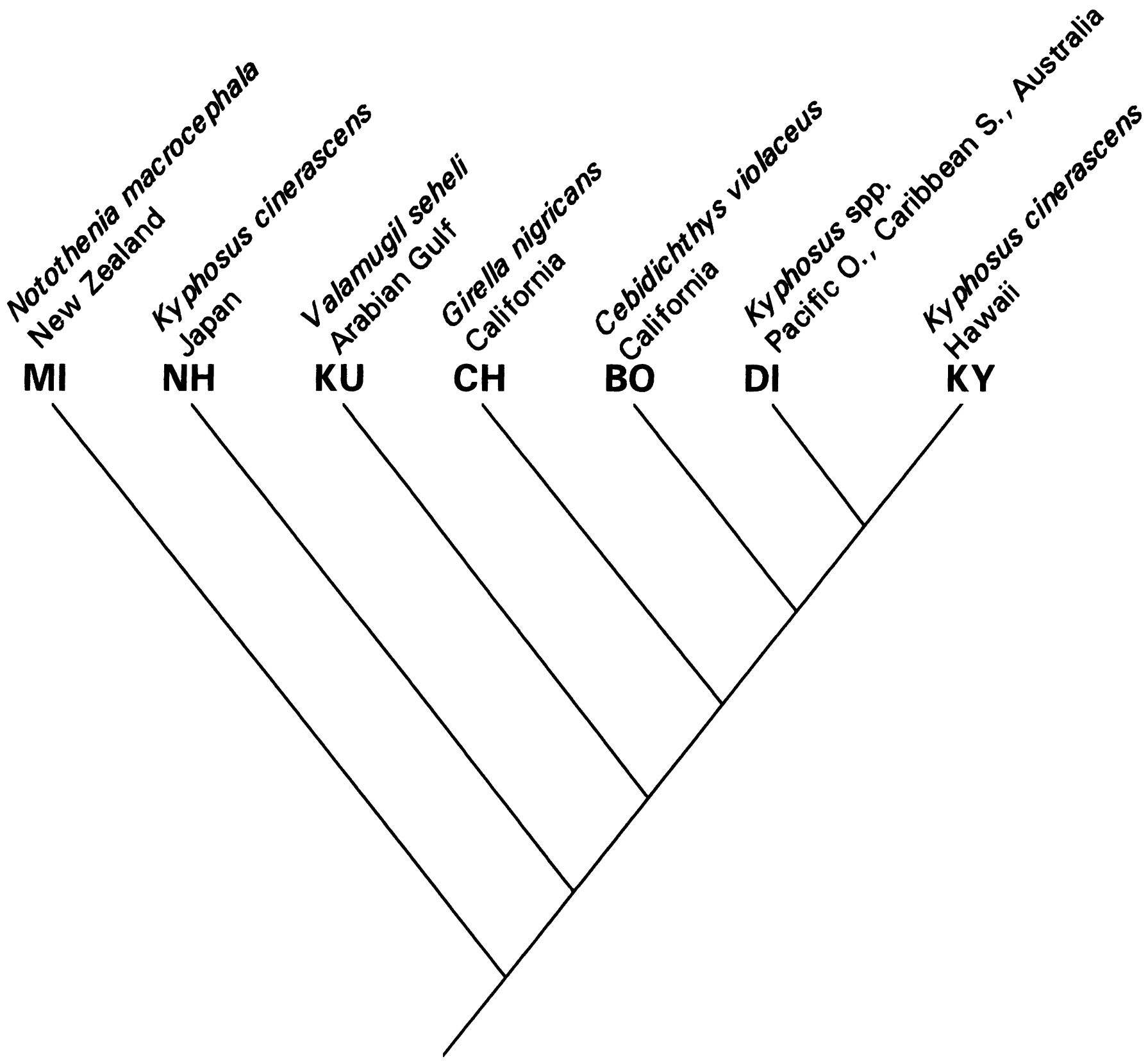

FIGURE 2. Optimization of geographic distribution and hosts onto phylogenetic tree for Mitrostoma, Neopisthadena, and Opisthadena species.

for previous observations by Brooks and McLennan (1993a, 1993b) and Pérez-Ponce de León and Brooks (1995a, 1995b) that parasitic platyhelminths seem to have experienced little secondary simplification during their evolutionary history.

Manter (Van Cleave and Manter, 1948; Manter, 1949, 1965) considered the reef fish genus Kyphosus to be an interesting system for biogeographic and coevolutionary studies using helminth parasites. Kyphosus spp. and their helminth fauna laid the cornerstone for Manter's thoughts about what he called "parascript" (see Brooks and McLennan, 1993a). Manter (1965) proposed an Indo-Pacific origin of Kyphosus, with secondary dispersion to the Americas via Japan and Hawaii and to the Caribbean Sea via the eastern Pacific Ocean. Several Opisthadena species inhabit kyphosid and related girellid hosts, so this study provides an oportunity to examine Manter's ideas in the light of current methods of phylogenetic and biogeographic analysis.

The phylogenetic tree depicts Mitrostoma nototheniae from New Zealand as the sister species of the rest of the clade (Fig. 2). The next branching point separates Neopisthadena habei, found in Japan from the 5 species of Opisthadena found in the Arabian Sea, Pacific Ocean, and Caribbean Sea. The New Zealand, then Japan plus Arabian Sea, and American Pacific distributions suggest a circum-Pacific ancient distribution of the group. Within the Opisthadena clade, the Arabian species $O$. kuwaiti is the sister species of the rest. The next 2 species, $O$. cheni and $O$. bodegensis, occur along the California coast. $O p$ isthadena bodegensis is the sister species of $O$. kyphosi, the 
Hawaiian endemic, plus $O$. dimidia, which is widely distributed throughout the Pacific Ocean and is the only member of the genus currently known from the Caribbean Sea. This particular geographic pattern does not support Manter's view of a progressive dispersion from the western to the eastern Pacific Ocean, suggesting rather that the Hawaiian endemic and its widespread sister species are derived from the eastern Pacific Ocean. The geographic distribution of $O$. dimidia is also interesting. Other hemiurids, such as Derogenes varicus, are extremely widespread in the marine environment, but those species tend to exhibit little host specificity. Opisthadena dimidia, by contrast, inhabits only members of the genus Kyphosus. The species is found in geographic areas lacking other members of the genus (the Caribbean Sea and Australia) and also sympatrically with its sister species, $O$. kyphosi, and with non-sister species inhabiting kyphosids and girellids $(O$. habei and $O$. cheni). Its occurrence in the Caribbean Sea supports Manter's (1965) views of colonization of the Caribbean Sea from the eastern Pacific Ocean. Because $\boldsymbol{O}$. dimidia is a highly derived, rather than a basal, member of its clade, it is not reasonable to suggest that it is a widespread ancestral generalist from which the other members of the group are derived. Its distribution pattern is more likely the result of secondary colonization of areas and hosts that are suitable for its survival (the occurrence of its sister species in the same species of host in Hawaii might indicate that $O$. kyphosi originated as a result of allopatric speciation). It is also possible that the widespread occurrence of $O$. dimidia, including its presence in the Caribbean Sea, is the result of anthropogenic phenomena, thus representing recent dispersal of the species. In either case, the species is a highly successful colonizer.

Four species of Opisthadena and Neopisthadena (O. dimidia, O. kyphosi, $N$. habei) are restricted to fishes of the Kyphosidae or the related Girellidae $(O$. cheni) and they, together with $O$. kuwaiti and $O$. bodegensis, which do not inhabit kyphosids or girellids, constitute a clade in the phylogenetic tree. The hosts for Mitrostoma nototheniae and for Genolinea and Neotheletrum are not kyphosids or girellids, suggesting that the association between kyphosids and girellids and this clade of digeneans originated with the common ancestor of Opisthadena plus Neopisthadena. If so, the occurrence of $O$. kuwaiti and $O$. bodegensis in a host that is neither a kyphosid nor a girellid would best be interpreted as the result of speciation via host switching (a form of peripheral isolates allopatric speciation, see Brooks and McLennan, 1993a).

The host and geographic distribution patterns discussed above make it difficult to interpret the degree of evolutionary association between kyphosids and girellids and Opisthadena. A possible solution would be to treat Opisthadena as a single data source, then assemble additional phylogenetic trees for other parasite groups inhabiting the same hosts and combine them in a single analysis to see if the parasite groups supported any general geographic or host relationships (Brooks parsimony analysis in Wiley, 1988a, 1988b; Brooks, 1981, 1990; Brooks and McLennan, 1991, 1993a). In this case, phylogenetic studies of groups such as Cadenatella Dollfus, 1948, Jeancadenatia, Dollfus, 1948, Enenterum Linton, 1910, Deontacylix Linton, 1910 (Digenea), and Filisoma Van Cleave, 1928 (Acanthocephala) could provide the additional parasite data necessary to ask if the geographic distribution and host patterns indicated by
Opisthadena are unique to that group or are part of a general pattern of marine evolutionary diversification.

\section{ACKNOWLEDGMENTS}

Funding for this study was provided by PADEP-UNAM proy. 3333-1994 and 3344-1996 to V.L.R., PAPIIT-UNAM proy. IN201593 to GPPL and NSERC Operating Grant No. A7696 to D.R.B. Special thanks to Dr. Ralph Lichtenfels, curator, and Dr. Eric Hoberg, United States National Parasite Collection, Dr. Masaaki Machida, curator, National Science Museum Helminth Collection, Tokyo, and Dr. Shunya Kamegai, curator, and Dr. Jun Araki, Meguro Parasitological Museum for the loan of specimens.

\section{LITERATURE CITED}

Al-Yamani, F. Y., AND F. M. NahHas. 1981. Digenetic trematodes of marine fishes from the Kuwaiti coast of the Arabian Gulf. Kuwait Bulletin of Marine Science 3: 1-22.

Bravo-Hollis, M. 1965. Helmintos de peces de aguas mexicanas del Pacífico. XXIV. Descripción de Opisthadena cortesi n. sp. (Tremátodo). Anales del Instituto de Biología de la Universidad Nacional Autónoma de México. Serie Zoología 36: 141-145.

BRoOKS, D. R. 1981. Hennig's parasitological method: A proposed solution. Systematic Zoology 30: 229-249.

- 1990. Parsimony analysis in historical biogeography and coevolution: Methodological and theoretical update. Systematic Zoology 39: 14-30.

ior: A research program in comparative biology. University of Chicago Press, Chicago, Illinois, 434 p.

, AND - 1993a. Parascript: Parasites and the language of evolution. Smithsonian Institution Press, Washington, D.C., 429 p. , AND - 1993b. Macroevolutionary patterns of morphological diversification among parasitic flatworms (Platyhelminthes: Cercomeria). Evolution 47: 495-509.

- , R. T. O'Grady AND D. R. GLEN. 1985. Phylogenetic analysis of the Digenea (Platyhelminthes: Cercomeria) with comments on their adaptive radiation. Canadian Journal of Zoology 63: 411-443.

GibSON, D. I., AND R. A. BRAY. 1979. The Hemiuroidea: Terminology, systematics and evolution. Bulletin of the British Natural History Museum (Zoology) 36: 35-146.

HenNig, W. 1966. Phylogenetic systematics. University of Illinois Press, Urbana, Illinois, 263 p.

Johnson, W. F., AND J. E. COPSEY. 1953. Opisthadena bodegensis n. sp. (Trematoda) from Dillon Beach, California. Transactions of the American Microscopical Society 72: 78-81.

León-Règagnon, V., G. Pérez-Ponce de León, and L. García-Prieto. 1997. Description of Heteroplectanum oliveri sp. n. (Monogenea: Diplectanidae) and comments on the helminth fauna of Kyphosus elegans (Perciformes: Kyphosidae) from Chamela Bay, México. Journal of the Helminthological Society of Washington. 63: (in press).

Linton, E. 1910. Helminth fauna of the Dry Tortugas. II. Trematodes. Carnegie Institution Publications 133: 11-98.

MACHIDA, M. 1980. Hemiurid trematodes of Kyphosus collected around Cape Shionomisaki, Kii Peninsula. Memoirs of the Natural Science Museum, Tokyo 13: 113-120.

MANTER, H. W. 1947. The digenetic trematodes of marine fishes of Tortugas, Florida. American Midland Naturalist 38: 257-416.

- 1949. An additional trematode from Tortugas, Florida, and a new name for Opisthoporus Manter, 1947, preoccupied. American Midland Naturalist 41: 432-435.

- 1954. Some digenetic trematodes from fishes of New Zealand Transactions of the Royal Society of New Zealand 82: 475-568.

- 1965. Parasites of fishes as biological indicators of recent and ancient conditions. In Host-parasite relationships. Proceedings of the XXVI Annual Biology Colloquium, J. E. McCauley (ed.) Oregon State University Press, Corvallis, Oregon, p. 59-71.

. 1966. A peculiar trematode, Gorgocephalus kyphosi gen. et 
sp. n. (Lepocreadiidae: Gorgocephalinae subfam. n.), from a marine fish of South Australia. Journal of Parasitology 52: 347-350.

MarTin, W. E. 1978. Digenetic trematodes of the marine fish, Girella nigricans (Ayers), from southern California with the description of two new species. Proceedings of the Helminthological Society of Washington 45: 175-181.

OVERSTREET, R. M. 1969. Digenetic trematodes of marine teleost fishes from Biscayne Bay, Florida. Tulane Studies in Zoology and Botany 15: $119-176$.

Pearson, J. C. 1992. On the position of the digenean family Heronimidae: An inquiry into a cladistic classification of the Digenea. Systematic Parasitology 21: 81-166.

Pérez-Ponce de León, G., AND D. R. Brooks. 1995a. Phylogenetic relationships of the genera of the Pronocephalidae Looss, 1902 (Digenea: Paramphistomiformes). Journal of Parasitology 81: 267277.

, AND — 1995b. Phylogenetic relationships among the species of Pyelosomum Loss, 1899 (Digenea: Pronocephalidae). Journal of Parasitology 81: 278-280.

SIERRA, R. N. A. 1984. Descripción taxonómica de algunos tremátodos parásitos de peces marinos de la zona del Caribe Mexicano. Thesis. Facultad de Ciencias, Universidad Nacional Autónoma de Mexico, Mexico, D.F., 89 p.

SkRJABIN, K. I. 1955. Trematody jivotnyj i cheloveka. Osnovy trema- todologii, Vol. XI. Isdatelstvo Akademii Nauk SSSR, Moskva, U.S.S.R., 743 p.

Sogandares-Bernal, F. 1959. Digenetic trematodes of marine fishes from the Gulf of Panama and Bimini, British West Indies. Tulane Studies in Zoology and Botany 7: 17-117.

SwOFFORD, D. 1993. Phylogenetic analysis using parsimony. Version 3.1.1. Illinois Natural History Survey, Urbana, Illinois, p. XXX.

Tang, C. T. Z. M. Shi, Cao Hua, J. Z. Guan, and C. S. Pan. 1983. Trematodes from marine fishes from Fujian. I. Hemiurids. Acta Zootaxonomica Sinica 8: 33-42.

Van Cleave, H., and H. W. Manter. 1948. A new species of the acanthocephalan genus Filisoma from the Dry Tortugas, Florida. Journal of Parasitology 33: 487-490.

WILEY, E. O. 1981. Phylogenetics. The theory and practice of phylogenetic systematics. John Wiley and Sons, New York, New York, $439 \mathrm{p}$.

. 1988a. Vicariance biogeography. Annual Review of Ecology and Systematics 19: 513-542.

1988b. Parsimony analysis and vicariance biogeography. Systematic Zoology 37: 271-290.

, D. Siegel-Causey, D. R. Brooks, and V. A. Funk. 1991. The compleat cladist: A primer of phylogenetic procedures. University of Kansas Museum of Natural History Press, Lawrence, Kansas, $158 \mathrm{p}$.

YAMAGUTI, S. 1970. The digenetic trematodes of Hawaiian fishes. Keigaku Publishing Co., Tokyo, Japan, 436 p. 